\title{
EL CAMBIO DE USO DEL PATRIMONIO HISTÓRICO COMO DINAMIZADOR ECONÓMICO Y DEL TURISMO CULTURAL
}

\author{
Dra. Margarita Barrera Cañellas ${ }^{1}$ \\ Escuela Universitaria de Turismo Felipe Moreno \\ mbarrera@etb-baleares.es \\ Dra. Luciana Melo Pereira ${ }^{2}$ \\ Escuela Universitaria de Turismo Felipe Moreno \\ Imelo@etb-baleares.es \\ Dr. Javier Franconetti Manchado ${ }^{3}$ \\ Escuela Universitaria de Turismo Felipe Moreno \\ ifranchonetti@etb-baleares.es
}

Para citar este artículo puede utilizar el siguiente formato:

Margarita Barrera Cañellas, Luciana Melo Pereira y Javier Franconetti Manchado: "El cambio de uso del patrimonio histórico como dinamizador económico y del turismo cultural", Revista Caribeña de Ciencias Sociales (vol 10, № 7 julio-septiembre 2021, pp. 239-253. En línea:

https://doi.org/10.51896/caribe/GBUE6514

\section{RESUMEN}

El agotamiento de los modelos tradicionales del turismo basado en "sol y playa" es un hecho que reflejan los mercados, que empiezan a buscar un turismo alternativo y más sostenible en los lugares que visita. Así, se está produciendo un crecimiento significativo del turismo cultural que permite la reutilización del Patrimonio Cultural de los enclaves turísticos tradicionales, actualizando los modelos productivos. Aun así, la nueva oferta del turismo cultural ha de ser creativa y atractiva para que satisfaga las cada vez mayores exigencias y expectativas de este segmento de mercado que generalmente opta por una autogestión de sus itinerarios. El objetivo de este trabajo es proponer un uso distinto del patrimonio en la isla de Mallorca a través de la instalación de una cámara oscura en la Torre des Verger, como ejemplo

\footnotetext{
${ }^{1}$ Doctora en Antropología por la Universidad Complutense de Madrid (UCM).

Profesora titular de la Escuela Universitaria de Turismo Felipe Moreno (EUTFM) y tutora de la Universidad Nacional de Educación a Distancia (UNED).

2 Doctora en Dirección y Planificación del Turismo por la Universidad de A. Coruña (UDC).

Profesora titular de la Escuela Universitaria de Turismo Felipe Moreno (EUTFM) y tutora de la Universidad Nacional de Educación a Distancia (UNED).

${ }^{3}$ Doctor en Economía Aplicada y Estadística para Empresa por la Universidad Nacional de Educación a Distancia (UNED).

Profesor titular de la Escuela Universitaria de Turismo Felipe Moreno (EUTFM), profesor de la Universitat des IIles Balears (UIB) y tutor en la Universidad Nacional de Educación a Distancia (UNED).
} 
de aprovechamiento innovador del patrimonio de la isla. A partir de una metodología de análisis cualitativo proyectivo realizamos una propuesta de aprovechamiento, restauración y explotación turística de un bien cultural, basado en experiencias creadas en otras localizaciones, que han optado por el desarrollo de este tipo de proyectos y en las cuales se ponen en juego conceptos tan innovadores como el marketing sensorial, orientado a hacer de su visita una experiencia inolvidable. Así conseguimos crear una nueva atracción turística orientada al turismo cultural que tiene como elemento añadido el propio sostenimiento económico del bien al margen de las subvenciones públicas.

Palabras clave: Sostenibilidad, Turismo, Patrimonio Cultural, Marketing Sensorial, Innovación.

\title{
THE CHANGE IN THE USE OF HISTORICAL HERITAGE AS AN ECONOMIC AND CULTURAL TOURISM STIMULUS
}

\begin{abstract}
The exhaustion of the traditional models of tourism based on "sun and sand" is a fact that is reflected in the markets, which are beginning to look for alternative and more sustainable tourism in the places they visit. Thus, there is a significant growth in cultural tourism, which allows for the reuse of the cultural heritage of traditional tourist sites, updating production models. Even so, the new cultural tourism offer has to be creative and attractive in order to satisfy the increasing demands and expectations of this market segment, which generally opts for self-management of its itineraries. The aim of this work is to propose a different use of heritage on the island of Mallorca through the installation of a camera obscura in the Torre des Verger, as an example of innovative use of the island's heritage. Using a qualitative projective analysis methodology we have developed a proposal for the use, restoration and tourist exploitation of a cultural asset, based on experiences created in other locations, which have opted for the development of this type of project and in which innovative concepts such as sensory marketing are brought into play, aimed at making the visit an unforgettable experience. In this way we manage to create a new tourist attraction oriented towards cultural tourism that has as an added element the economic sustainability of the property itself outside of public subsidies.
\end{abstract}

Keywords: Sustainability, Tourism, Cultural Heritage, Sensory Marketing, Innovation.

\section{INTRODUCCIÓN}

Illes Balears, por su situación y paisaje, es un referente nacional e internacional del turismo. Gracias a ello, la generación de riqueza relacionada con este sector ha permitido mantener a esta comunidad autónoma entre las más prosperas del estado español.

Hoy en día casi el $50 \%$ de la riqueza y el empleo están relacionados en las islas directamente con el turismo. En términos de empresas, algo menos del 30\% también están vinculadas con este sector (IBESTAT: 2018). 
Estos datos son consecuencia del modelo de explotación turística utilizado, vinculado a un turismo de masas, que llega en temporada alta a igualar al número de residentes, con los problemas logísticos que ello representa para los habitantes, tanto en recursos energéticos e hídricos, como en infraestructuras o incluso servicios sociales básicos como el sanitario, entre otros.

Este modelo turístico está basado principalmente en explotar el "sol y playa", favoreciendo la llegada de un turista de bajo nivel adquisitivo bajo la reserva del "todo incluido", basado en precios a la baja y que perjudica directamente a la oferta indirecta y complementaria vinculada al turismo: restaurantes, cafeterías, tiendas de recuerdos.

Además, desde hace unos años, el turismo de cruceros ha presentado un crecimiento exponencial. Así, durante 2017, entre cruceros de base y tránsito, pasaron por los puertos de Illes Balears casi 2,8 millones de personas (IBESTAT: 2018). Este tipo de turismo genera una riqueza muy concentrada en el lugar de desembarco y en las zonas turísticas de interés muy cercanas; pero por contra, ocasiona efectos muy negativos en la saturación del uso de los recursos de dichas zonas.

Ambos modelos de turismo, y teniendo en cuenta la enorme importancia que guardan para la economía de Illes Balears, adolecen de dos componentes que afectan enormemente a la misma y son la estacionalidad propia de la actividad y su insostenibilidad.

De ambos, el componente estacional es la causa del enorme peso que el trabajo de "temporada" tiene en las islas, siendo la comunidad autónoma líder en España, en el uso del contrato "fijo discontinuo", motivo fundamental de que en Illes Balears se tenga una de las pensiones medias de jubilación más bajas del Estado (IBESTAT, 2018).

Por otro lado, el número cada vez mayor de visitantes, cuya fuerte evolución podemos ver en el gráfico 1, aboca a un uso excesivo de los recursos materiales y también naturales en temporada alta (Sansó, 2016), que obligan a tomar en consideración la necesidad de implementar modelos turísticos más respetuosos con el medio ambiente y, en definitiva, más sostenibles en el tiempo. 


\section{Gráfico 1.}

Visitantes en las Islas Baleares

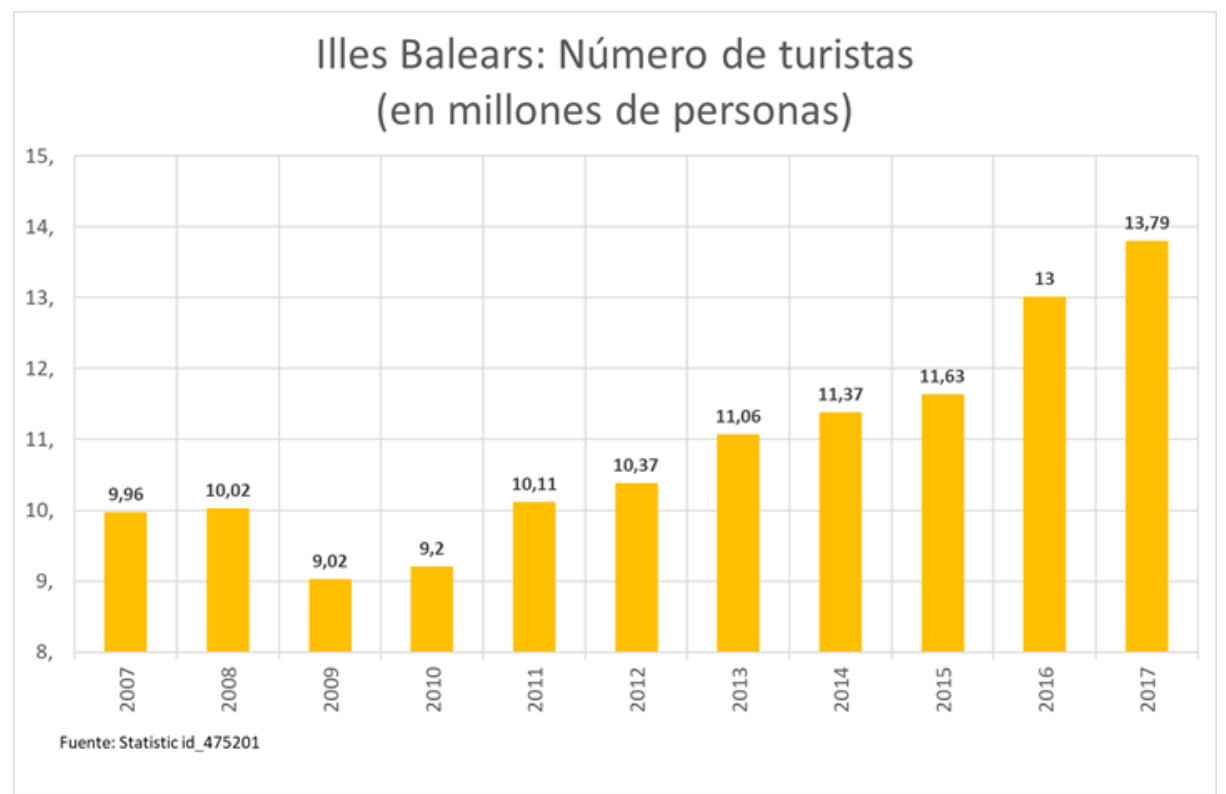

Fuente: IBESTAT, 2018

El escenario descrito no es único ni exclusivo de las Illes Balears, sino generalizado en gran parte de los enclaves turísticos a nivel mundial y augura en el futuro reciente, un obligado cambio en la demanda turística hacia destinos que disfruten de un mayor componente de bienestar medioambiental.

Además, otro problema que se detectado es que debido a la saturación de visitantes y recursos se está generando un rechazo a tener en cuenta por parte de las sociedades de acogida, incluida la balear, hecho que influye de forma negativa en la propia industria turística, ya que no se ven los turistas bien acogidos por las poblaciones locales.

Este escenario de comportamiento creciente del número de visitantes año tras año, representa el caldo de cultivo perfecto para que surja, en la población residente, la creciente sensación de saturación. Pero esta situación y esta sensación no son nuevas, ya que se han registrado situaciones similares en el escenario balear en el pasado reciente.

Los autores Carles Manera y Ferran Navinés destacan esta percepción en la población de las islas durante los años 90 , con una economía balear en pleno auge, y que debido al excesivo crecimiento en número de visitas, levantó voces críticas en aras de frenar el ritmo, yendo las líneas más extremas a ir en contra públicamente de la llegada de más turistas, $(2018,152)$

Como vemos, existe una clara necesidad de la sociedad de potenciar formas alternativas de turismo que sean sostenibles desde todos los puntos de vista: económico, social y cultural, y que se adapte además a una demanda cada vez más diversificada y personalizada, (González Fernández y López Guzmán, 2011); y es en este marco, en que el turismo cultural junto al turismo de reuniones, 
también llamado MICE (Meetings, Incentives, Conventions and Exhibitions), tienen la posibilidad de ser los grandes motores de la industria turística en España en el futuro próximo, siempre y cuando seamos conscientes de que debemos conseguir darles un enfoque creativo (Cunchillos, 2017), concibiendo en conjunto un turismo sostenible desde parámetros socio-culturales y medioambientales que permita mantener la identidad cultural y natural del enclave turístico, a la vez que se produce una explotación rentable de los bienes patrimoniales (De Juan,2010).

En este contexto proponemos como objetivo utilizar un recurso disponible en Illes Balears, poco presente en la actividad turística de forma efectiva: su Patrimonio Cultural, pero, orientando su uso hacia una perspectiva eficiente y productiva de corte económico, y no, como hasta ahora, como elemento histórico inerte vinculado a la financiación pública para su sostenimiento y conservación, haciendo que sea un pilar básico en el desarrollo en las islas de un turismo cultural de corte sostenible, que elimine o al menos minimice los efectos negativos de saturación y temporalidad y participe como atractor en otros tipos de turismo, en concreto el turismo de reuniones.

\section{METODOLOGÍA}

El método utilizado fue cualitativo con confiabilidad y validez de una investigación cualitativo (Hernández, Fernández, Baptista, 2010; Martínez, 2006).

Sumado a esto, el estudio se utiliza un análisis documental y bibliográfico. Para Marconi e Lakatos (2007, p.71) abarca "la revisión de la bibliografía ya tornada pública en relación al tema de estudio, desde revistas, libros, periódicos, tesis, entre otros". Lo que para perfeccionar, Manzo apud Marconi e Lakatos (2012, p. 32) "se preocupa, por lo tanto, con aspectos de la realidad que no se pueden ser cuantificados, centrándose en la comprensión y explicación de la dinámica social”.

Como también, la presente investigación se caracteriza por ser un trabajo proyectivo de nivel descriptivo, orientado a la elaboración de una propuesta dónde se aplica el marketing sensorial en un espacio caracterizado por su importancia histórica cultural. En coherencia con la afirmación de Hurtado (2016, p. 36) establece la investigación proyectiva "consiste en la elaboración de una propuesta, un plan o un modelo, como solución a una problemática o necesidad de tipo práctica, partiendo de un diagnóstico preciso de las necesidades del momento".

\section{EL PATRIMONIO HISTÓRICO CULTURAL COMO APUESTA DEL TURISMO MICE}

El turismo MICE o de reuniones se encuentra estrechamente relacionado con el turismo cultural, ya que éste es una parte fundamental de sus programas sociales y de acompañantes, y además ayuda de forma inequívoca al desarrollo de formas turísticas sostenibles, puesto que este turismo centrado en la organización de varias tipologías de eventos, genera altos beneficios en las ciudades que lo acogen, 
donde además hacen uso de la oferta complementaria que ofrecen, y ello sin desplazar grandes masas de visitantes más que en contadas ocasiones, (Flamarich y Duro,2011).

El perfil del turista MICE lo hace idóneo como consumidor de turismo cultural, ya que demuestra un gran interés por los valores culturales y patrimoniales de los lugares que visita, al margen de su participación en las actividades programadas dentro de las sesiones de trabajo o formativas a las que asiste, siendo frecuente su llegada o partida días antes de las sesiones, y la repetición del destino en vacaciones de corte familiar.

Este visitante posee en general, un nivel cultural y de ingresos medio-alto, que invierte en visitas y actos culturales, buscando un conocimiento más o menos profundo del lugar que visita, a la par que pasa desapercibido para la población local, tanto por su respeto por la cultura de acogida, como por su número, significativamente menor que el turismo de masas de sol y playa, (Arcila, Sánchez, Chica, Soto, Pliego, Azzariohi, 2011). Sin embargo, se calcula que tiene un gasto medio tres veces superior al del turista de "sol y playa".

En este contexto actualizado, otro factor que hemos de tener en cuenta, es que se ha producido una redefinición y actualización del Patrimonio Cultural y su concepto clásico, más allá de sus significados identitarios, puesto que el patrimonio se contempla hoy como recurso y se valora como factor de desarrollo (García Canclini, 1999), visiones que son perfectamente compatibles entre ellas como nos indica Cluzeau (2000).

Según Aguilar (1999), en España la primera muestra de interés hacia el patrimonio ocurrió en paralelo al proceso de formación de las comunidades autónomas, cuando se extendió la conveniencia política de marcar límites y dar consistencia histórica y cultural a cada espacio autonómico, apoyándose en la capacidad simbólica que los elementos patrimoniales de cada uno poseen, los cuales detentan elementos identitarios suficientemente eficaces a la hora de legitimar las distintas identidades culturales. Por esto, para Madariaga (2002) es fundamenta la aplicabilidad que tiene el patrimonio y su posibilidad de llevar a la práctica las ideas de pertenencia desde su objetivación social, lo que ha provocado una mayor aceptación del cambio del concepto tradicional de bienes patrimoniales.

El patrimonio es ahora visto como un recurso valioso para el sector turístico, y superada ya esa primera etapa de identificación política, es recuperado y promocionado con el fin de diversificar la actividad económica y el desarrollo de cada territorio autonómico, promoviendo acciones eficientes y sostenibles de reconocimiento de la herencia cultural, que posibilitan el progreso social y económico de su entorno, haciendo que la necesidad de financiación pública para su supervivencia no sea imprescindible.

Además, la importante revolución y diversificación que ha experimentado la actividad turística en todas sus tipologías estos últimos años, principalmente con la introducción de las nuevas tecnologías y las redes sociales, las cuales han creado una mayor exigencia, nuevos gustos, necesidades y expectativas en los clientes/turistas, han supuesto nuevos desafíos y una serie de cambios trascendentales en la estructura y la utilización de los espacios de carácter patrimonial para prácticas 
turísticas especializadas, exclusivas y distintas a las habituales, que utilizan estos sitios como sedes singulares cada vez más frecuentemente.

A la vista de lo expuesto y en consonancia con ello, Flamarich y Duro (2011) apunta que dos de las características principales del turista cultural son, en primer lugar, que su gasto medio en destino es tres veces superior a la media del turista de "sol y playa" y en segundo lugar, posee un nivel adquisitivo alto, lo que a la postre genera una especial predilección por ese tipo de turista en los diferentes destinos, pues es un visitante respetuoso no solo con el medio ambiente y geográfico, sino con la sociedad que le acoge, su cultura y costumbres.

Por tanto, el fomento de nuestro patrimonio y su conservación ha de ser una prioridad para nosotros, pero no únicamente desde un punto de vista cultural y/o sostenible, sino también desde un punto de vista económico y productivo, ya que debemos de dotarlo de nuevos usos para no hacerlo gravoso a las instituciones públicas y propietarios, y hacer que sea rentable y activo económicamente, lo que redunda sin duda en una mejor conservación del mismo. Así, un ejemplo significativo del uso de un bien patrimonial para fines turísticos y de desarrollo económico es la experiencia de la Cámara Oscura de la ciudad de Cádiz (España), situada en la Torre Tavira de esta ciudad.

\subsection{El uso del patrimonio histórico cultural: el caso de la Torre Tavira (Cádiz)}

La Torre Tavira (figura 1) es una torre vigía construida en el siglo XVIII que fue designada como tal en el año 1778 por su altura de más de 45 metros sobre el nivel del mar. Está situada en el centro histórico de la ciudad de Cádiz y forma parte del Palacio de los Marqueses de Recaño, siendo nombrada bien de interés cultural (BIC) en el año 2005. Desde ella podemos observar una de las mejores vistas sobre la ciudad. En la actualidad es de titularidad pública ya que pertenece al Ayuntamiento de Cádiz, aunque desde el año de 1994 es de gestión privada a través de una concesión administrativa.

\section{Figura 1:}

Vista de la Torre Tavira.

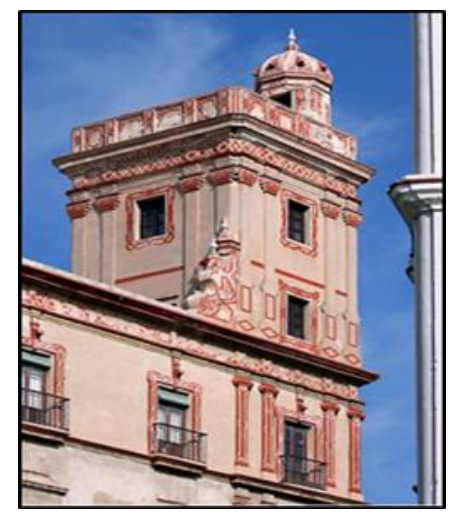

Fuente: https://www.camaraoscuraworld.com/torre-tavira-cadiz/ 
La Torre Tavira cuenta en sus instalaciones con una de las atracciones patrimoniales pioneras en España: La Cámara Oscura.

Este edificio histórico alberga en su interior dos salas de exposiciones y un mirador, desde el cual puede admirarse, como ya hemos apuntado, todo el casco histórico de la ciudad. En la primera sala de exposiciones el espacio, como podemos observar en la figura 2, se dedica a la explicación pormenorizada del funcionamiento de una cámara oscura, a la historia de este ingenio a lo largo de los años y a la mención y localización geográfica de otras cámaras oscuras repartidas por España y por el resto del mundo.

\section{Figura 2:}

Sala de exposiciones

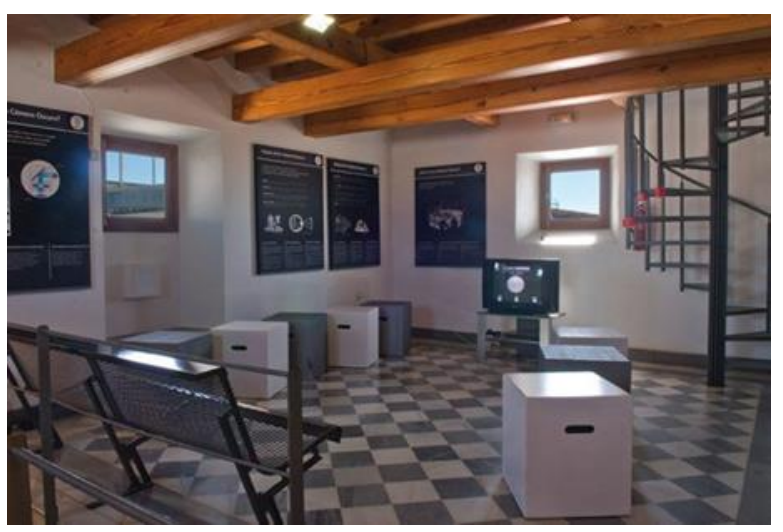

Fuente:https://www.tudestino.es/andalucia/provincia-de-cadiz/cadiz-capital/sugerencia/guias-turisticosvisitas-culturales/torre-tavira-camara-oscura/

En la segunda sala de exposiciones, que podemos contemplar en la figura 3, encontramos un conjunto explicativo dedicado a la ciudad de Cádiz, entre los siglos XVIII y XIX, que nos describe el funcionamiento del Puerto de Cádiz en el siglo XVIII, cuáles eran las rutas comerciales con América, dónde se encontraban las casas de los armadores y comerciantes, e incluso se hacen alusiones históricas en sus paneles explicativos a las Cortes de Cádiz de 1812. 


\section{Figura 3:}

\section{Sala de exposiciones}

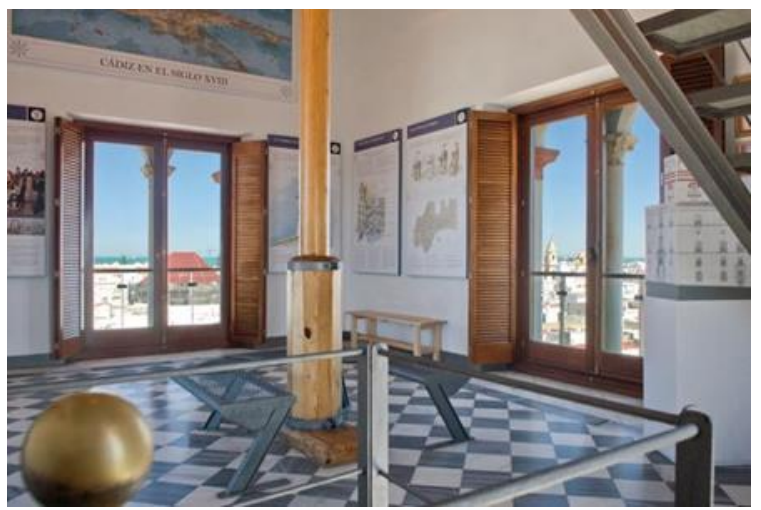

Fuente:https://www.tudestino.es/andalucia/provincia-de-cadiz/cadiz-capital/sugerencia/guias-turisticosvisitas-culturales/torre-tavira-camara-oscura/

En el piso superior, dentro ya del interior del mirador, encontramos la Cámara Oscura, inaugurada en el año 1994. Ésta es un observatorio dotado de un ingenio óptico que, a base de espejos y un periscopio, como podemos observar en la figura 4, permite a los visitantes acceder a un recorrido visual de 360 grados por toda la ciudad de Cádiz a través de imágenes reales y en movimiento, que es conducido por un guía que va relatando a lo largo del itinerario visual la historia y curiosidades de la ciudad.

El funcionamiento consiste en la creación de una imagen a partir del reflejo de un juego de espejos, sobre una pantalla en blanco de formato curvilíneo horizontal, con función de mesa, que se encuentra ubicada en el centro de una habitación totalmente a oscuras, pintada de negro,

La imagen que se proyecta es en color, muy luminosa, y refleja lo que sucede en el exterior de la torre, en tiempo real y en movimiento. Además, dada la larga distancia focal de las lentes principales, el resultado es un espectacular efecto óptico que hace que los objetos situados a mucha distancia parezcan cercanos (Figura 4).

La pantalla está en movimiento constante, sube y baja a fin de enfocar las diferentes distancias y lugares. Las imágenes pueden también girar hacia delante y hacia atrás para visualizar diferentes perspectivas del paisaje.

La duración de cada sesión es de aproximadamente 15-20 minutos, en pases de media hora, en diferentes idiomas, ininterrumpidamente durante todo el día. 


\section{Figura 4:}

Funcionamiento de la Cámara Oscura.

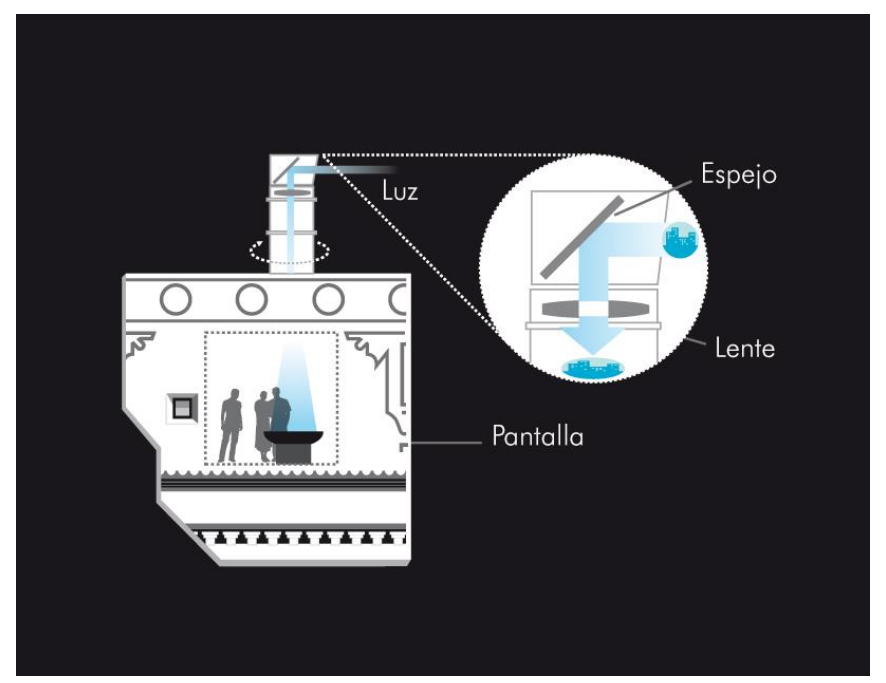

Fuente:https://i1.wp.com/www.torretavira.com/wp-content/uploads/2015/02/funcionamiento-torre-taviracadiz-01.jpg?ssl=1

Torre Tavira posee hoy la patente para España del modelo de utilidad de la Cámara Oscura № U9701729, concedida por la Oficina Española de Patentes y Marcas, lo que propicia, además del desarrollo turístico de la ciudad y de su propia promoción como atracción cultural, su difusión hacia otras localidades que quieran y tengan las condiciones necesarias para explotarla como atractivo turístico de sus localidades ofreciendo una experiencia inolvidable a sus visitantes.

\section{Figura 5:}

Cámara Oscura de la Torre de Tavira

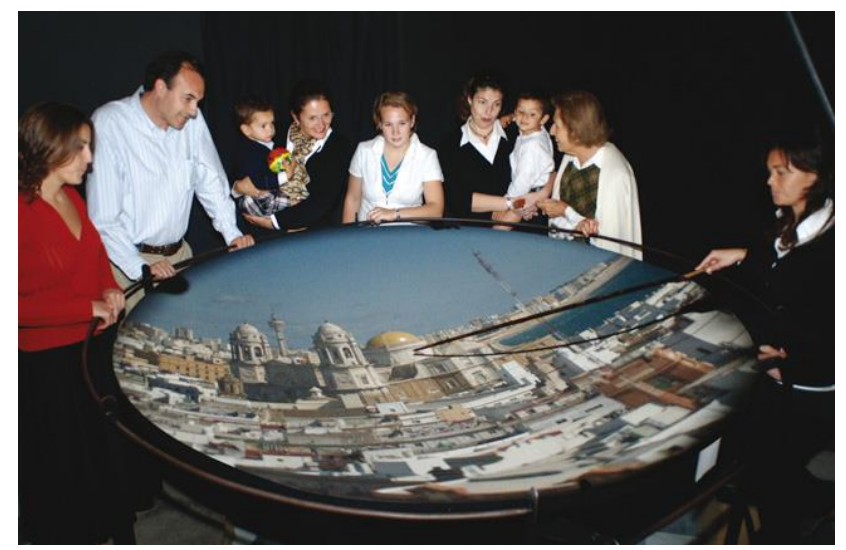

Fuente: https://www.torretavira.com/wp-content/uploads/2015/02/camara-oscura-torre-tavira-04.jpg 
La Cámara Oscura, como hemos visto, es un proyecto en marcha y un ejemplo de desarrollo y aprovechamiento de un bien patrimonial, que combina cultura con una experiencia sensorial, a través de la cual se visualiza el entorno de una manera nada convencional, y realmente puede ser una alternativa innovadora de desarrollo para las localidades que deseen utilizar sus bienes patrimoniales desde una perspectiva eficiente, productiva y sostenible, como atestiguan los datos relativos a la Torre Tavira: "La Cámara Oscura es uno de los equipamientos culturales y turísticos más visitado cada año en la ciudad, con más de 100 mil personas y en el año 2018 fue el más visto" (Diario Cádiz, 2019).

\subsubsection{La Cámara oscura como propuesta eficiente del Patrimonio histórico cultural balear}

Si nos situamos nuevamente en el contexto balear, la isla de Mallorca cuenta dentro de su patrimonio cultural con un conjunto importante pero poco visible: una red de torres antiguas de vigilancia, catalogadas, pero poco conocida en general.

En concreto existen treinta y nueve torres en el interior y once en la costa, siendo algunas de ellas un sitio idóneo para la implantación de una Cámara Oscura por los paisajes que las rodean, sobre todo aquellas que se encuentran en la Sierra de Tramuntana o en sus inmediaciones, ya que permitirían el acceso visual al entorno de esta localización geográfica nombrada Patrimonio Mundial por la Unesco en el año 2011 debido a la excelencia de su paisaje cultural, ejemplo de convivencia entre el hombre y el medio.

Hemos elegido ejemplo la llamada Torre des Verger. La torre en cuestión se encuentra sobre el acantilado de la punta de Es Verger, el mismo que da su nombre, situado entre las poblaciones mallorquinas de Estellencs y Banyalbufar., en plena Sierra de Tramuntana.

Esta torre construida a lo largo del año 1579 sobre el emplazamiento de una vieja barraca de vigilancia, y desde ella se recibían y emitían señales a los barcos que se aproximaban a la costa, o aviso a las poblaciones del interior sobre la presencia de buques corsarios o piratas.

Fue adquirida por el Archiduque Luis Salvador de Austria, mecenas y pionero del turismo en las Islas Baleares, en una subasta del Estado en 1875, dejándola en herencia posteriormente a sus herederos.

En el año 1995 pasó por un proceso de restauración y actualmente es un monumento sobre el que se está trabajando para que vuelva a ser de titularidad pública, y el Ayuntamiento de Banyalbufar y la Consellería de Cultura del Consell de Mallorca, son los responsables de su supervisión

En la actualidad se accede a la torre (figura 6) a través de un pequeño puente hacia la roca madre donde se levanta la atalaya. La construcción es de sección circular, de 4,78 metros de diámetro y de 2,70 metros de altura. Está edificada con un sistema de mampostería o argamasa (mezcla de piedra pequeña y cal), y en su interior se puede ascender por un estrecho portal en forma de arco de medio punto, que da paso a una pequeña cámara cubierta por una bóveda, de unos 3,80 metros cuadrados. Dentro de esta pequeña habitación encontramos una pequeña escalera de hierro, que nos permite 
acceder al piso superior. En el tejado se construyó un pequeño porche, donde se refugiaban de la lluvia y el viento los vigilantes. Este tejado reposa sobre un parapeto de unos 2,70 metros de altura, que desciende siguiendo la pendiente de las tejas. En este parapeto encontramos una ventana y tres troneras.

\section{Figura 6:}

Visión de la Torre de Es Verger

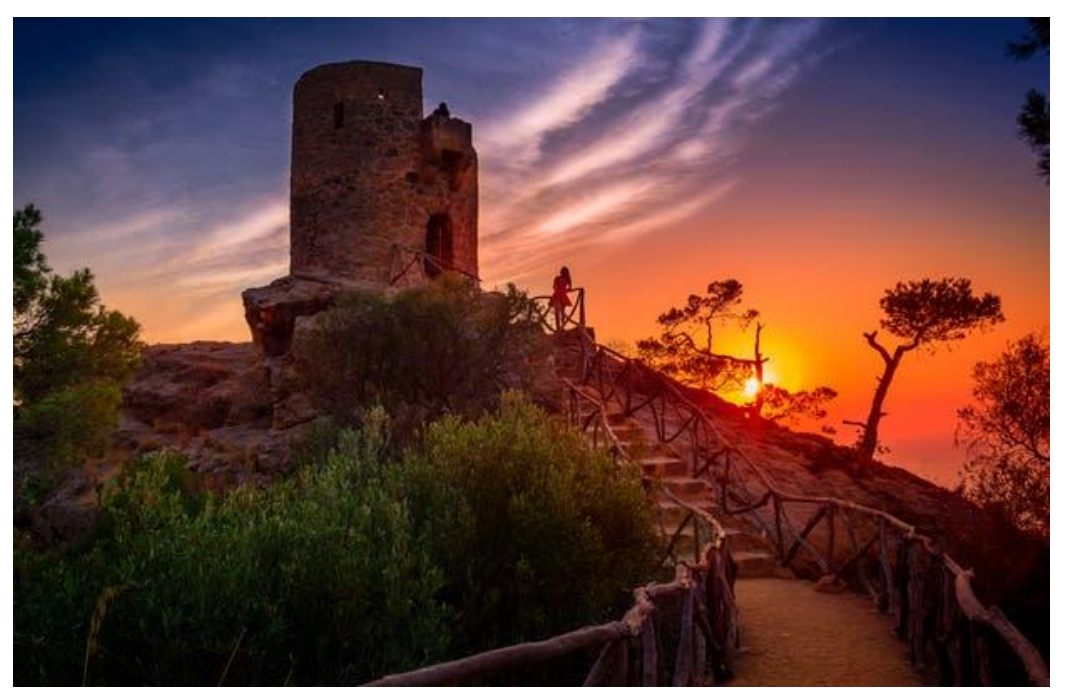

Fuente:https://photo620x400.mnstatic.com/00eb011c2a54f9bd79d76e5efd36bfab/torre-de-ses-

animes.jpg

Además de sus características físicas, la Torre es considerada un lugar encantado por los lugareños, como muchos otros en Mallorca, y también posee las mejores vistas del norte de la isla, ya que desde ella podemos apreciar la costa y acantilados de la Sierra de la Tramuntana. Ya el mismo Archiduque, Vo Erzherzog Ludwing Salvator, en su publicación dedicada a las Islas Baleares, titulada Die Balearen (1897) describe este enclave como: "el mejor panorama de toda la costa de la Isla de Mallorca".

La propuesta de recuperación y utilización que hacemos de este bien patrimonial se lleva a cabo a través de una planificación estratégica basada en el marketing mix, ofreciendo además una experiencia de marketing sensorial, en la que los efectos producidos por los estímulos externos (sensoriales) 0 internos (sensaciones, emociones, pensamientos) de uno o varios sentidos, desempeñan un papel determinante para el proceso de visita.

Según Krishna (2012) el marketing sensorial involucra los sentidos e impacta las percepciones, creencias, juicios y comportamientos. Para López (2015) el objetivo es sorprender, conectar con las personas, creando para ello actividades originales que implican a los sentidos, a las expectativas e invitan a la acción.

Por lo tanto, específicamente, en la Torre de Es Verger, a priori, se utilizará el sentido de la visión a través de la Cámara Oscura para generar estímulos sensoriales en los visitantes y turistas, ya que como lo plantean Lindgren y Nordström (2009), el ser humano vive en un mundo visual, donde el sentido 
de la vista ha sido definido como "el sentido más seductor, que tiene el poder de convencernos a pesar de no tener una lógica real" (Lindstrom, 2005), ya que a través de la vista el ser humano comprende el entorno que lo rodea, porque la visión no sólo se considera como el sentido más significativo del hombre, sino también la parte del sistema sensorial más dominante (Schiffman, 2001) y será esa visión nada convencional del entorno la que estimularemos en el proyecto.

La implantación de la Cámara Oscura en la Torre de Es Verger es totalmente factible por su carácter de bien de interés cultural (BIC) que por sí solo atrae la atención de los visitantes y turistas, un atractivo que además apoyan las leyendas, historias y misterios relacionadas a lo largo de los años con la torre y sus alrededores ya que de hecho es popularmente conocida como la Torre de Ses Ànimes (Torre de las Ánimas), que la hacen única y autentica, además de su privilegiada situación sobre el acantilado.

Todos estos elementos, forman parte del plan impulsor de una actividad turística organizada y planificada en este entorno, a través del marketing sensorial (visual) con la implantación de la Cámara Oscura en uno de sus espacios, a los que se añaden exposiciones, paseos guiados con relatos reales, y la utilización de otros recursos audiovisuales como las holografías o el video mapping.

Para ello, la definición del producto (Cámara Oscura), su precio (según el mercado a que va ser direccionado), su distribución (los canales más adecuados de comercialización) y finalmente su promoción/publicidad (cómo se dará a conocer), deberán ser establecidos y respaldados por una cooperación entre el sector público y privado, a fin de planificar, coordinar, fomentar y estimular la puesta en marcha de este proyecto.

\section{CONCLUSIONES}

Con el diseño planteado, podemos afirmar que se crea un producto turístico pionero en las Islas Baleares y que además es una buena alternativa a la hora de ampliar la oferta ofrecida al turismo cultural en la isla, que busca nuevas experiencias, las cuales se encuentran complementadas por la propia historia del enclave, el halo de misterio que envuelve la torre y su relación con el Archiduque Luis Salvador, que le presta una notoriedad sobre la cual generar futuras acciones publicitarias (campañas de marketing) articuladas entorno a su figura.

Su explotación turística generará unos ingresos que se invertirán en preservar y proteger la propia torre, siendo así una oferta cultural sostenible y comprometida con la conservación del medio, el patrimonio cultural y la identidad propia de la isla.

Así, posibilitamos la explotación turística de los Bienes de Interés Cultural, facilitando la supervivencia del patrimonio de titularidad pública, pero de propiedad privada, asegurando su continuidad a la vez que se desarrolla un turismo cultural sostenible desde el punto de vista medioambiental, cultural y social, y simultáneamente se proporcionan los medios económicos suficientes para el sostenimiento patrimonial autónomo sin dependencia de las instancias públicas. 
La planificación y desarrollo de estas nuevas propuestas turísticas beneficia de forma directa a los propietarios de todos los Bienes de Interés Cultural, ya que dándoles un uso creativo y recreativo, pero respetuoso, se rentabilizan y se asegura su supervivencia, beneficiándose los visitantes, al poder vivir una experiencia sensorial única, con lo que aunamos oferta y demanda de tal forma que la riqueza producida por el turismo, en este caso cultural, se repartirá de manera más equilibrada a través del tejido social, y nuestro Patrimonio Histórico y Etnológico se conservará de forma adecuada con todas las garantías para su supervivencia en el tiempo.

\section{REFERENCIAS}

Aguilar Criado, E. (1999). Entre la tradición y la modernidad: las artesanías, una propuesta de análisis, en Patrimonio Etnológico. Nuevas perspectivas de estudio. Instituto andaluz del Patrimonio Histórico, Junta de Andalucía, Sevilla.

Arcila Garrido, M., Sánchez, J.L., Chica A., Soto, A. Pliego, C., Azzariohi, A. (2011). Puesta en valor del patrimonio cultural como factor turístico: una aproximación al caso de la provincia de Cádiz y de la región Tánger-Tetuán, en Arqueología y Turismo en el Círculo del Estrecho, pp.69-82.

Cámara Oscura World $(20$ de septiembre de 2021). Disponible en https://www.camaraoscuraworld.com/torre-tavira-cadiz/

Cluzeau, C. (2000): Origet du. Le tourisme cultural. Puf, Paris.

Cunchillos, C. (2017). "Turismo de reuniones y sostenibilidad" en La Voz del Sector, Punto MICE, núm.19 http://puntomice.com/turismo-de-reuniones-y-la-sostenibilidad/ [Consulta el 4 de septiembre de 2018]

DECRETO 95/2005, de 29 de marzo, por el que se declara Bien de Interés Cultural, con la categoría de Monumento, el inmueble denominado Torre Tavira, en Cádiz. Sevilla. 2005.

De Juan Alonso, José María (2010). Turismo sostenible en el Mediterráneo, panorama y perspectivas, estrategias y acciones. Documento de Trabajo, UICN, Cámara Málaga, Málaga.

Diario de Cádiz. (6 de febrero 2019). Disponible en: www.diariodecadiz.es. Acceso: 2019, 07 de febrero.

Flamarich, M. y Duro, J.A. (2011). "Turismo de negocios (eventos) en España: análisis y perspectivas" en Papers de Tourisme, núm.4, pp 59-74.

García Canclini, N. (1999). Los usos sociales del patrimonio cultural, en Patrimonio etnológico. Nuevas perspectivas de estudio. Instituto Andaluz del Patrimonio Histórico, Sevilla.

González Fernández, V. y López-Guzmán, T. (2011). Política turística de un destino singular: Melilla (España), en Aldaba núm. 35, pp. 3-35.

Hernández, R., Fernández, C. Y Baptista, P. (2010). Metodología de la investigación (5ta ed.). México: McGraw-Hill.

Hurtado, J. (2016). Metodología de la Investigación Holística. Venezuela: Fundación Sypal, P. 36

IBESTAT. (2018). Datos anuales de la actividad turística. Disponible en: http://ibestat.caib.es/ibestat/estadistiques/tur/. Acceso: 2018, 20 de diciembre. 
Krishna, A. (2012). An integrative review of sensory marketing: Engaging the senses to affect perception, judgment and behavior. Journal of Consumer.

Lindstrom, M. (2005). Brand Sense: Sensory Secrets Behind the Stuff We Buy, New York.

Lindgren, B. and Nordström, G. (2009). Det kreativa ögat. Om perception, semiotik och bildspråk. Lund: Studentlitteratur.

Madariaga, C J. (2002). La comercialización del patrimonio cultural. Turismo y patrimonio histórico. Instituto Andaluz del Patrimonio Histórico, Junta de Andalucía, Sevilla.

Manera, C. \& Navinés, F. (2018). La industria invisible: 1950-2016: el desenvolupament del turisme a l'economia balear. Lleonard Muntaner, Palma de Mallorca.152

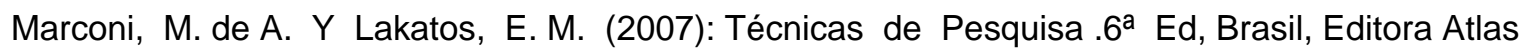

Marconi, M. de A y Lakatos, E. M. (2012): Metodologia do trabalho científico: Procedimentos Básicos, Pesquisa Bibliográfica, Projeto e Relatório Publicações e Trabalhos Científicos. 7. ed., Brasil, Atlas.

Página Oficial Atracción Cámara Oscura Torre Tavira. (2019). Disponible en: www.torretavira.com. Acceso: 2019, 08 de enero.

Sansó, A. (2016). Projeccions de la càrrega demográfica diària de les Illes Balears per a diferents horitzons temporals (archivo PDF). Recuperado el 25 de febrero de 2020, de http://www.caib.es

Schiffman, H.R. (2001): Sensation and Perception: An Integrated Approach. New York: John Wiley \& Sons, Inc.

Tu destino (2021) Disponible en: https://www.tudestino.es/andalucia/provincia-de-cadiz/cadizcapital/sugerencia/guias-turisticos-visitas-culturales/torre-tavira-camara-oscura/

Torre Tavira (2021) Disponible en:

https://photo620x400.mnstatic.com/00eb011c2a54f9bd79d76e5efd36bfab/torre-de-sesanimes.jpg

Vo Erzherzog Ludwing Salvator. (1897): Die Balearen. Unveränderter Faksimile-Reprint des Originals von 1897. 2 Bände Saarbrücken 2011. 